\title{
Low host-tree preferences among saproxylic beetles: acomparison of four deciduous species
}

\author{
Per Milberg, Karl-Olof Bergman, Helena Johansson and Nicklas Jansson
}

\section{Linköping University Post Print}

\section{Tweet}

N.B.: When citing this work, cite the original article.

Original Publication:

Per Milberg, Karl-Olof Bergman, Helena Johansson and Nicklas Jansson, Low host-tree preferences among saproxylic beetles: acomparison of four deciduous species, 2014, Insect Conservation and Diversity, (7), 6, 508-522.

http://dx.doi.org/10.1111/icad.12074

Copyright: Wiley: 12 months

http://eu.wiley.com/WileyCDA/

Postprint available at: Linköping University Electronic Press

http://urn.kb.se/resolve?urn=urn:nbn:se:liu:diva-111927 
Low host-tree preferences among saproxylic beetles: a comparison of four deciduous species

Running title: Host tree preference among saproxylic beetles

PER MILBERG, ${ }^{1}$ KARL-OLOF BERGMAN, ${ }^{1}$ HELENA JOHANSSON ${ }^{1}$ and NICKLAS JANSSON ${ }^{1,2}$

${ }^{1}$ IFM Biology, Conservation Ecology Group, Linköping University, SE58183 Linköping, Sweden

${ }^{2}$ County Administration Board of Östergötland, 58186 Linköping, Sweden

Correspondence: Per Milberg, IFM Biology, Linköping University, SE58183 Linköping, Sweden. E-mail: permi@ifm.liu.se

Fax: not available

Telephone: +46 705173100 (mobile)

5400 words

1 Table

4 Figures

1 Appendix 


\begin{abstract}
1. Many wood-dwelling beetles rely on old hollow trees. In Europe, oaks are known to harbour a species-rich saproxylic beetle fauna, while less is known regarding other broad-leaved tree species. Furthermore, the extent to which saproxylic insect species have specialised on different tree species remains unknown.
\end{abstract}

2. In this study, we sampled beetles through pitfall traps and window traps in four different tree species in a landscape with many old oaks.

3. We recorded 242 saproxylic beetle species of which 27 were red-listed. After eliminating the species recorded only on a single tree, few cases among the 171 remaining species in the dataset were confined to a single tree species.

4. Using odds ratios, we showed that 19 of the 171 beetle species showed significant associations with Quercus robur in at least one of the two trap types. For Acer platanoides, Fraxinus excelsior and Tilia cordata, the corresponding numbers were 6 , 2 and 5, respectively. One species showed a negative association with Quercus robur.

5. Using meta-analysis, we quantified the degree of association between the beetle species and the tree species. The associations were most profound among species classified as obligate saproxylic rather than facultative in lifestyle.Overall, a significant association was only found with Quercus robur.

6. We conclude that the saproxylic fauna is dominated by non-specialist species but includes a small proportion of truly tree-host-specific species. Furthermore, other broad-leaved trees can be important as supporting habitats for many saproxylic organisms that have had presumed associations with oaks to date.

Keywords. beetle, broad-leaved tree, coleoptera, conservation, hollow, saproxylic, preference

\title{
Introduction
}

When trees become older, structures serving as microhabitats for many organisms begin to develop (Sverdrup-Thygeson et al., 2009). Hollows in tree trunks often contain wood mould, which is loose wood colonised by fungi and with remains from bird nests, insects and dead leaves (Ranius, 2002; Jansson et al., 2009a). Hollows with wood mould in old trees harbour a rich and specialised insect fauna (Dajoz, 2000). Forestry and changes in land management have reduced the density of old trees (Speight, 1989; Hannah et al., 1995; Kirby \& Watkins, 1998; Eliasson \& Nilsson, 2002), and many saproxylic insects have consequently become rare and are the focus of conservation efforts.

Saproxylic insects are, at least for some part of their life cycle, dependent on dead wood (Speight, 1989). The degree of food specificity is likely to vary among species, from those exclusively relying on dead wood (obligate) to those with greater flexibility (facultative), and there have been attempts to classify saproxylics accordingly (e.g., Tavakilian et al., 1997; Dodelin et al., 2008; Jansson et al. 2009a). Although many saproxylic insects have been classified as specific to host tree genera and some even as monophagous to a single tree species, the evidence is often weak (e.g., faunistic surveys and field-workers' impressions). Furthermore, studies report conflicting results (Jonsell et al., 2007; Irmler et al. 1996). One general conclusion, though, seems to be that the degree of host specificity in an assemblage decreases with increasing wood decay (Jonsell et al., 1998; Grove, 2002; Wu et al., 2008). This 
might explain why Jonsell et al. (2007) reported differing assemblages of saproxylics on logging residues (aspen, birch, oak, spruce; relatively fresh), while Irmler et al. (1996) did not when comparing logs and stumps (beech, alder, spruce).

Conservation management and related assessments would benefit from better information about host specificity among saproxylics. For example, old oaks have been the exclusive focus in many studies within Europe and adjacent areas (e.g., Ranius and Jansson, 2000, 2002; Ranius, 2002; Franc et al., 2007; Müller and Goßner 2007; Buse et al., 2008, 2013; Ranius et al., 2009; Andersson et al., 2014), as well as in conservation efforts (e.g., Jansson et al., 2009a, 2009b; Sverdrup-Thygeson et al., 2009; Ranius et al., 2011; Bergman et al., 2012), but other broad-leaved tree species might also be important to consider as supporting habitats for insects presumed to be oak specialists (Musa et al. 2013).

Surprisingly, the current knowledge of tree host specificity among saproxylic species seems to be based on expert judgment only, as we have failed to find studies comparing different tree species using a strict sampling protocol. Although expert judgements are what we often rely on when dealing with the autecology of insects, obvious shortcomings are their qualitative nature, their lack of transparency and the risk for observation bias. Hence, to further this field of enquiry, quantitative studies are needed that specifically target host specificity by comparing resource selection. Therefore, the aim of the current study was to investigate to what extent saproxylic beetle species prefer hollow trees of different species. We selected, within our northern European study system, large specimens of oak and three other deciduous tree species and sampled them with pitfall and window traps. We expect a better understanding of the habitat requirements of rare saproxylic beetles, and especially those considered as oak dependent, to be useful in landscape planning and conservation efforts.

\section{Materials and Methods}

\section{Study sites}

This study was conducted in one of the few remaining landscapes in Northern Europe with a high density of old oaks, in Östergötland, south-eastern Sweden (Antonsson \& Wadstein, 1991). Hollow trees of the different tree species, registered over the past 15 years in a database at the County Administration Board of Östergötland, were used to select potential trees in a study area of approximately $10 \times 30 \mathrm{~km}^{2}$. In total, 49 hollow trees were selected, clustered at 10 study sites. At each site, at least one hollow Quercus robur was examined, along with one or several hollow trees of Acer platanoides, Fraxinus excelsior and/or Tilia cordata. The distance between two trees belonging to the same site was between 14 and $2603 \mathrm{~m}$. In the study area, the old and hollow deciduous trees were approximately $68 \%$ Quercus robur, $6 \%$ Acer platanoides, $6 \%$ Fraxinus excelsior and $8 \%$ Tilia cordata, according to the database at the County Administration Board.

\section{Beetle trapping}

Beetles were collected using two types of traps: pitfall traps and window traps. According to a study comparing these two methods to survey saproxylic beetles (Ranius \& Jansson, 2002), window traps collect the highest number of species. On the other hand, pitfall traps collect beetles clearly associated with tree hollows, which 
window traps do not. Therefore, to be able to catch a wide variety of saproxylic species, a combination of these two methods was chosen for this study.

The pitfall trap was a plastic jar of 7-cm diameter placed in the tree hollow with the opening level with the wood mould surface. The window trap was a $30 \times 50 \mathrm{~cm}^{2}$ vertical transparent plastic plate with a tray underneath, and it was placed near (within $1 \mathrm{~m}$ ) the entrance of the tree hollow (Figure 1). The positions of the windows were 1.5-4 $\mathrm{m}$ above the ground, depending on where the hollow entrance was situated on the tree. The trays were filled to $70 \%$ with a solution of approximately $50 \%$ water, $50 \%$ propylene glycol, some denatured alcohol to prevent animals from drinking the solution, and a few drops of detergent to reduce surface tension. We trapped beetles from May until late August and the traps were emptied four times during that period.

The target in this project was to have one oak with one or several of the other tree species per site, with one pitfall trap and one window trap on each tree. This target was not reached for two main reasons. It proved difficult to find hollow non-oaks that allowed pitfall traps (entrance too narrow; wood mould without reach), and several of the window traps were destroyed during the season. In total, 49 trees contributed the data used: 38 trees with both trap types, seven with only a pitfall trap and four with only a window trap.

\section{Identification of saproxylic beetles}

Nicklas Jansson (NJ) identified most of the saproxylic beetles genera to the species level, while other experts were consulted for the remaining genera (see Acknowledgments). The family Latrididae was excluded from the study for financial reasons. Species were classified as obligate or facultative saproxylic according to Dodelin et al. (2008), with a few exceptions that, based on field experience (NJ), were classified as obligate saproxylic (see Appendix). Non-saproxylic species were excluded from the study. Nomenclature follows Lundberg (1995) and the red-list categories of Gärdenfors (2010).

\section{Data analyses}

First, we compiled the number of beetle species unique to a tree species and those unique to a single tree. These cases of singletons were numerous and, although interesting to compile, at the species level, they provide very weak evidence for host specificity. Therefore, they were excluded from the meta-analyses detailed below.

As we wanted to put the study within the framework of estimates of effect sizes, rather than hypothesis testing (Cumming, 2012; Milberg, 2014), we decided to use odds ratios, an index that is biologically interpretable, comparable over studies and study systems and well suited for meta-analysis. Odds ratios compare proportions (Lechowicz, 1982; Lele et al., 2013), and they are used frequently in some fields of research, less frequently in ecology (Rita \& Komonen, 2008), and sometimes appear as Jacobs' Index (Jacobs, 1974) in the resource selection literature. The odds of finding a beetle species on a particular tree species (i.e., the probability of finding it divided by the probability of not finding it) was divided by the odds of finding it on the other tree species. Odds ratios were calculated using the software Comprehensive Metaanalysis (v2.2, 2011). These species-wise odds ratios were then used to calculate an overall weighted odds ratio for each tree species and trap type and for obligate and facultative saproxylic species as groups. Assuming a null model of no host specificity, $\log$ (odds ratios) would be normally distributed around zero. For the 57 species 
recorded with both trap types, we also calculated species-wise estimates of host preferences as $\ln$ (odds ratios).

\section{Results}

More than 5,600 individuals of saproxylic beetle species were identified in this study as belonging to 242 species. Some saproxylic beetles were very abundant: 13 species had more than 100 individuals, the most abundant being Atheta nigricornis with 903. In contrast, 63 were represented by single individuals, and eight additional species were confined to single trees. Neither these singletons nor richness seemed to vary among the tree species in the pitfall trap data (Table 1). In the window-trapped data, there was a tendency for singletons to be fewest on Fraxinus excelsior, while Quercus robur had the most species and the most singletons (Table 1). The vast majority of singletons were those of a single individual caught, providing poor evidence for host specificity. Therefore, the eight cases of singletons where a beetle species was found on more than one tree provide stronger evidence of specificity. There were 2, 1,2 and 3 such species restricted to Acer platanoides, Fraxinus excelsior, Quercus robur and Tilia cordata, respectively.

Of the total number of species caught, 27 were on the Swedish red-list (Gärdenfors 2010), all being obligate saproxylic and mainly appearing in the window traps (Appendix). Among these species, 15 were found on Quercus robur, while Acer platanoides, Fraxinus excelsior and Tilia cordata had 8, 7 and 9 red-listed species, respectively.

\section{Species-wise odds ratios}

In total, the 171 species generated 217 cases of calculated odds ratios (i.e., some species were found in both trap types). There were 20 species, and 25 cases, where the odds ratio suggested a significant association with Quercus robur. Corresponding values for the other tree species were 6 species and 7 cases for Acer platanoides, 2 species and 2 cases for Fraxinus excelsior, and 5 species and 5 cases for Tilia cordata (Figure 2a). Only one of the significant associations was negative: Anobium nitidum avoided Quercus robur (Figure 2a). Of the 39 cases with significant odds ratios, 4 involved facultative and 35 obligate saproxylic beetle species (Figure 2a).

Among the 57 species that were recorded in both trap types and for which overall averages were calculated, there were 16 species (and 20 cases) where the odds ratio suggested a significant association with a tree species (Figure 2b). Two of the 16 species were facultative, while the rest were classified as obligate saproxylic species. In this analysis, Quercus robur, Acer platanoides, Fraxinus excelsior and Tilia cordata had 10, 3, 1 and 0 significantly positively associated species, respectively (Figure 2b). In contrast, there were several negatively associated species: three each for Quercus robur and Acer platanoides (Figure 2b).

Obligate saproxylic beetles with host tree preferences

There were obligate saproxylic species associated with each of the four tree species, in both pitfall and window trap data. Most of the obligate saproxylic species were found on oaks, and those for which we provide strongest evidence - i.e., present in both datasets - were Allecula morio, Ampedus spp., Anaspis thoracica, Dorcatoma spp., Euglenes oculatus, Mycetophagus piceus, Paromalus flavicornis; Figure 2b). 
Acer platanoides had five obligate species significantly associated with it (Figure 2a), but it was also represented by more trees in the study (Table 1), giving it stronger statistical power. Combining the evidence from both trap types resulted in three species with a clear preference for Acer platanoides (Anobium nitidum, Mycetochara axillaris, Phloeophagus lignarius) and three that avoided it (Cryptophagus dentatus, Dorcatoma chrysomelina, Prionychus ater; Figure 2b).

Fraxinus excelsior had only one species clearly associated with it: Prionychus ater (Figure 2). For Tilia cordata, there were four cases with positive associations and one case with a negative association, but because results from the two trap types were conflicting, none were significant in the species-wise meta-analyses (Figure 2a, b).

It is noteworthy that for three beetle species, the species-wise meta-analysis highlights a positive association with one tree species and a negative association with another, thus supporting a strong degree of host preference in these species (Anobium nitidum, Dorcatoma chrysomelina, Prionychus ater; Figure 2b).

Facultative saproxylic beetles with host tree preferences

Only four of the 39 facultative saproxylic species recorded showed a significant association with one tree species, and then only in one of the trap types (Figure 2a). Furthermore, no species showed positive associations in the species-wise metaanalyses, which instead highlighted two with negative associations (Figure 2b).

\section{Quantifying the degree of host specificity}

The meta-analysis, calculating the weighted average of trap- and species-wise odds ratios, showed that the degree of preference for oak was much higher than for the other three tree species, which instead resided close to the reference line (Figure 3 ). For oak, the preference was only apparent among obligate species, but in both trap types (Figure 3).

Facultative species were relatively few, and consequently the $\log$ (odds ratios) had large confidence intervals and overlapped zero in all eight cases (Figure 3). In contrast, three estimates involving the more numerous group of obligate species did not overlap the reference line (Figure 3).

Of the $868 \log$ (odds ratios) calculated, 39 were significantly different from zero (5\% level). Hence, approximately $4.5 \%$ of the cases displayed a clear preference. Of the 228 species-wise $\log$ (odds ratios) from the meta-analyses, 20 were significant $(8.8 \%)$. Corresponding values for evidence of non-preference, as indicated by $\mathrm{P}>0.5$, were $54 \%$ and $50 \%$, respectively.

Finally, using the best available species-wise data, i.e., the meta-analysis of 57 species collected in both trap types, and considering the distribution of $\log$ (odds ratios), there was little to suggest a preference for Acer platanoides, Fraxinus excelsior or Tilia cordata, which had symmetrically distributed values (Figure 4). In contrast, the distribution of $\log$ (odds ratios) for Quercus robur was skewed towards positive associations (Figure 4).

\section{Discussion}

We expected the best evidence for host specificity among the four tree species to be displayed in the data from pitfall traps because specimens caught could be considered 
to be more clearly associated with a particular tree species (i.e., pitfall traps are less affected by stray catches). On the other hand, window traps catch more specimens and more species (Table 1; Ranius \& Jansson, 2002), but they are likely to be biased towards species that are more mobile (e.g., early successional species) and species associated with habitats outside cavities (e.g., branches or under bark). Together, the two types of data provide two different perspectives, and their combination might give a relatively unbiased assessment of individual species. Hence, we put particular emphasis on the outcome of the species-wise meta-analyses (Figure 2a, Figure 4).

Generally, oak stood out by being more species-rich, with both a larger number of unique species and a larger number of significantly associated species. However, when considering the number of significant cases and the other tree species, the evidence points towards a fauna dominated by generalists, with a small proportion of host-specific species. Therefore, there is little evidence for saproxylic beetles being monophagous to any great extent. This is good news for conservation biologists, as polyphagous species have much larger feeding niches than monophagous species. For the conservation manager, it adds potential habitat and opens up an opportunity to include several tree species in conservation planning but also complexity as the tree species might differ in relative value as saproxylic habitats.

The present results are somewhat surprising because Quercus robur has been considered to be the most species-rich tree (Palm 1959; Lundberg, 1995; Jonsell et al., 1998, Müller and Goßner 2007; Irmler et al., 2010). Furthermore, a compilation of substrate requirements, including host specificity, of all red-listed saproxylic beetles in Sweden concluded that almost 30\% of the invertebrates found in $Q$. robur were considered monophagous (Jonsell et al., 1998). However, there seem to be no other systematic sampling studies comparing saproxylic fauna in hollows between tree species, but there are some studies investigating tree host specificity on other dead wood, with mixed results. Studies on high stumps (Lindhe \& Lindelöw, 2004; Lindhe et al., 2005) and on logging residues (Jonsell et al., 2007) of spruce, birch, aspen and oak found that the different tree species hosted different assemblages of saproxylic beetles. However, among the deciduous trees, there was considerable overlap, especially between birch and oak (Lindhe \& Lindelöw, 2004). Another study on logs and stumps found only small differences between the tree species beech, alder and spruce (Irmler et al., 1996). Müller \& Goßner (2007) hypothesised that the occurrence of insects on oak would be lower when a target oak was surrounding by Fagus sylvatica than when surrounded by oaks. This was the case for specialised leaffeeders, but not for saproxylic species. In the light of our results, the last finding is not unexpected is presumed oak specialists can use also beech.

In the current study, which was placed in an oak-dominated landscape, we should have expected a larger species pool on oak, and consequently more species caught, than for the other trees. However, such a pattern is only observed (and is still not significant) in the obligate saproxylic species. The study by Jonsell et al. (1998) was based on faunistic literature and field experience and might therefore be biased. Still, we acknowledge a weakness in the present methodology: we aimed for old trees with accessible hollows. However, it is impossible to select trees from different species that are identical in features such as age, size, shape, and geographic placement. Because the landscape is oak-dense, the oaks selected might be typical for a large population of old trees, while the other tree species are biased towards their "very best" specimens. We also acknowledge the possibility that, this being an oakdominated landscape, oaks might act as sources and the other tree species as sinks. 
Hence, the latter might carry more saproxylic beetles, and more oak-associated beetles, when surrounded by oaks than when in an oak-poor matrix. Such a pattern has been suggested by Irmler et al. (2010) when interpreting the finding that Fagus sylvatica had a higher number of saproxylic beetle species than oaks when in a $F$. sylvatica-dominated area in Germany.

Although trees other than oaks have been shown to be very species-rich (e.g., Jonsell \& Andersson, 2011) and to carry many of the same beetle species (e.g., Palm 1959), it is important to stress two features that distinguish oaks from the other tree species studied here. First, the oak trees are potentially older and larger, thereby providing on average - more wood mould per tree, and over a longer time period per tree. Second, impressions from the field (e.g., many hollows lacking wood mould) as well as data on rates of timber decomposition (e.g., Flæte et al., 2009), suggest that oak wood is slower to decompose, thereby creating more long-lasting wood mould. Therefore, we believe that oaks, compared with many other broad-leaved species, have a greater conservation value for saproxylics, but that the difference is one of quantity rather than quality. If this is correct, we might identify other tree species of particular value as saproxylic habitat, either through their size/age, or through their slow wood decomposition rate. Sweden, being poor in tree species, has few candidates to rival oak (possibly Fagus sylvatica), but the Mediterranean have several, e.g. Castanea sativa and Juglans regia.

One type of saproxylic species utilises the fruiting bodies of fungi, most often available outside the tree hollows, and it is claimed that such species can be hostspecific to the fungus, which, in turn, might be host-specific to a tree species (e.g., Jonsell \& Andersson 2011). We also expected host specificity to be found among those species specialising on dying or newly dead wood, which might be richer in deterring host-specific chemicals. Living trees and fungi would be more influenced by specific chemicals than would wood mould. There were, however, only four species among those with a host preference that can be considered as early successional (Cerylon spp., Cryptarcha undata, Epuraea guttata; Figure 2a), and none of these were highlighted in the species-wise meta-analysis (Figure 2b).

Quercus robur has been the focus in several studies of saproxylic beetles, including the hermit beetle (Osmoderma eremita; e.g., Ranius, 2002, Jansson et al., 2009b). In many respects, it is considered an oak-dependent species. Nevertheless, it was no great surprise that two out of four specimens in the present study were recorded in Tilia cordata, with the other two on Quercus robur (Appendix): O. eremita has been shown to strongly prefer Tilia cordata over $Q$. robur (and other tree species, such as Fraxinus excelsior and Acer platanoides) in Poland (Oleksa et al., 2007), and in a pan-European assessment, Tilia spp. was mentioned as the second most important tree among a long list of potential host tree species (Ranius et al., 2005).

Those species that, according to significant odds ratios, were associated with a particular tree species was partly in line with the existing literature (Palm 1959; Jonsell et al. 1998). The obligate saproxylic species Dorcatoma chrysomelina, Dorcatoma flavicornis, Mycetophagus piceus and Euglenes oculatus were found to be strongly associated with Quercus robur in this study. They are specialists on redrotten oak wood, and such wood is usually created through decay by the fungus Laetiporus sulphureus (Jansson et al., 2009a), a species prevalent on oaks (Vasiliauskas et al., 2003). In addition to its occurrence on oaks, Dorcatoma flavicornis was caught in a single window trap on Fraxinus exelcior (Appendix) and 
has previously been recorded on dead wood of Acer platanoides (Jonsell et al., 1998) and Tilia cordata in Sweden (Jonsell \& Sahlin, 2010). In the latter study, which sampled hollow Tilia cordata, Mycetophagus piceus and Euglenes oculatus were also found (Jonsell \& Sahlin, 2010). That study and Jonsell (2010) also report Dorcatoma chrysomelina on Tilia cordata. These mixed results show that even the species clearly associated with $Q$. robur have also been repeatedly recorded on other tree species (cf. Palm 1959). Of the species with a preference (Figure 2a) that were also reported on by Palm (1959), only two were listed by him to exclusively occur on oak: Ampedus hjorti, which we recorded on both oak and Tilia cordata (both trap types) and Epuraea guttata, that we recorded also on Acer platanoides and Fraxinus exelcior (window traps; Appendix).

Another way to manifest preference is by avoidance, but there were few species that displayed a distinct non-preference for a tree species in the current study. Despite many specimens collected, none of Anobium nitidum were on Quercus robur. Others have, however, reported it on this tree species. Palm (1959), in fact, note it on 13 of 14 deciduous tree species that this author distinguishes, and a previous study in our study region (Ranius \& Jansson 2000) recorded it on Quercus robur.

To conclude, only a few saproxylic beetle species were found to be host-specific. The cases of host specificity were mainly towards oak, and mainly involved obligate saproxylics species. From a conservation perspective, several tree species can contribute to the available saproxylic habitat for most species.

\section{Acknowledgments}

We thank the landowners for their permission to put up traps on their land and the entomologists Stig Lundberg and Rickard Andersson for identification of some of the specimens. Financial support to this project came from Eklandskapsfonden, the Municipality of Linköping and the County Administration Board of Östergötland. We are also grateful for insightful comments by Marcos Méndez and referees on previous versions of the manuscript.

\section{References}

Andersson, K., Bergman, K-O., Andersson, F., Hedenström, E., Jansson, N., Burman, J., Winde, I., Larsson, M.C. \& Milberg, P. (2014) High-accuracy sampling of saproxylic diversity indicators at regional scales with pheromones: the case of Elater ferrugineus (Coleoptera, Elateridae). - Biological Conservation, in press.

Antonsson, K. \& Wadstein, M., (1991) Eklandskapet. En naturinventering av hagar och lövskogar $i$ Eklandskapet söder om Linköping. Länsstyrelsen i Östergötlands län, Linköping (in Swedish)

Bergman, K.-O., Jansson, N., Claesson, K. Palmer, M.W. \& Milberg, P. (2012) How much and at what scale? Multiscale analyses as decision support for conservation of saproxylic oak beetles. Forest Ecology \& Management, 265, 133-141.

Buse, J., Zabranzky, P. \& Assmann, T. (2008) The xylobiontic beetle fauna of old oaks colonised by the endangered longhorn beetle Cerambyx cerdo (Coleoptera: Cerambycidae). Mitteilungen der Deutschen Gesellschaft für allgemeine und angewandte Entomologie, 16, 109-112. 
Buse, J., Assmann, T., Friedman, A.L.L., Pavlicek, T. \& Rittner, O. (2013) Woodinhabiting beetles (Coleoptera) associated with oaks in a global biodiversity hotspot: a case study and check-list for Israel. Insect Conservation \& Diversity, 6, 687-703.

Comprehensive Metaanalys, version 2.2 (2011) http://www.meta-analysis.com/

Cumming, G. (2012) Understanding The New Statistics: effect sizes, confidence intervals, and meta-Analysis. New York, Routledge.

Dajoz, R. (2000) Insects and forests. The role and diversity of insects in the forest environment. Intercept, Londres.

Dodelin, B., Ballot, P. \& Stokland, J.N. (2008) The saproxylic database checklist of beetles vers. 8/2008: www.saproxylic.org, visited in Dec 2010.

Eliasson, P. \& Nilsson, S.G. (2002) 'You should hate young oaks and young noblemen': the environmental history of oaks in eighteenth- and nineteenthcentury Sweden. Environmental History, 7, 659-674.

Flæte, P.O., Evans, F.G. \& Alfredsen, G. (2009) Natural durability of different wood species: results after five years testing in ground contact. Pp 65-70 in: The NordicBaltic Network in Wood Material Science and Engineering, Forest \& Landscape Working Papers 43/2009. http://www.nordicforestresearch.org/wpcontent/uploads/2011/03/2009_report_wse.pdf

Franc, N., Götmark, F., Økland, B., Nordén, B. \& Paltto, H. 2007. Factors and scales potentially important for saproxylic beetles in temperate mixed oak forest. Biological Conservation, 135, 86-98.

Gärdenfors, U. (2010) Rödlistade arter i Sverige 2010-The 2010 red list of Swedish species. Swedish Species Information Centre, SLU, Uppsala

Grove, S.J. (2002) Saproxylic insect ecology and the sustainable management of forests. Annual Review of Ecology \& Systematics, 33, 1-23.

Hannah, L., Carr, J.L. \& Lankerani, A. (1995) Human disturbance and natural habitat: a biome level analysis of a global data set. Biodiversity \& Conservation, 4, 128155.

Irmler, U., Heller, K. \& Warning J. (1996) Age and tree species as factors influencing the populations of insects living in dead wood (Coleoptera, Diptera: Sciaridae, Mycetophilidae). Pedobiologia, 40, 134-148.

Irmler, U., Arp, H. \& Nötzold, R. (2010) Species richness of saproxylic beetles in woodlands is affected by dispersion ability of species, age and stand size. Journal of Insect Conservation, 14, 227-235.

Jacobs, J. (1974) Quantitative measurement of food selection. Oecologia, 14, 413417.

Jansson, N., Ranius, T., Larsson, A. \& Milberg, P. (2009a) Boxes mimicking tree hollows can help conservation of saproxylic beetles. Biodiversity \& Conservation, 18, 3891-3908.

Jansson, N., Bergman, K-O., Jonsell, M. \& Milberg, P. (2009b) An indicator system for identification of sites of high conservation value for saproxylic oak (Quercus spp.) beetles in southern Sweden. Journal of Insect Conservation, 14, 399-412. 
Jonsell, M. (2010) Inventering av vedlevande skalbaggar - i lindmiljöer på öar i Hjälmaren. Länsstyrelsen i Örebro län, publ.nr. 2010:1. In Swedish.

Jonsell, M. \& Andersson, K. (2011) Vedleande skalbaggar på lind. [Sarpoxylic beetles on lime trees in Sweden.] Entomologisk Tidskrift 132, 167-186.

Jonsell, M. \& Sahlin, E. (2010) Inventering av vedlevande skalbaggar på lindar $i$ Södermanlands, Uppsala och Västmanlands län. Länsstyrelsen i Södermanland, rapportserie, 2010:12, ISSN 1400-0792. In Swedish.

Jonsell, M., Westlien, J. \& Ehnström, B. (1998) Substrate requirements of red-listed saproxylic invertebrates in Sweden. Biodiversity \& Conservation, 7, 749-764.

Jonsell, M., Hansson, J. \& Wedmo, L. (2007) Diversity of saproxylic beetle species in logging residues in Sweden - Comparisons between tree species and diameters. Biological Conservation, 138, 89-99.

Kirby, K.J. \& Watkins, C. (1998) The ecological history of European forests. CAP International, Oxon.

Lele, S.R., Merrill, E.H., Keim, J. \& Boyce, M.S. (2013) Selection, use, choice and occupancy: clarifying concepts in resource selection studies. Journal of Animal Ecology, 82, 1183-1191.

Lechowicz, M. J. (1982) The sampling characteristics of electivity indices. Oecologia, 52, 22-30.

Lindhe, A. \& Lindhelöw, A. (2004) Cut high stumps of spruce, birch, aspen and oak as breeding substrates for saproxylic beetles. Forest Ecology \& Management. 203, $1-20$.

Lindhe, A., Lindelöw, Å. \& Åsenblad N. (2005) Saproxylic beetles in standing dead wood density in relation to substrate sun-exposure and diameter. Biodiversity \& Conservation, 14, 3033-3053.

Lundberg, S. (1995) Catalagus Coleopterorum Sueciae. Naturhistoriska Riksmuseet. Stockholm, Sweden.

Milberg, P. (2014) Evidence-based vegetation management: prospects and challenges. Applied Vegetation Science, in press.

Müller, J. \& Goßner, M. (2007), Single host trees in a closed forest canopy matrix: a highly fragmented landscape? Journal of Applied Entomology, 131, 613-620.

Musa, N., Andersson, K., Burman, J., Andersson, F., Hedenström, E., Jansson, N., Paltto, H., Westerberg, L., Winde, I., Larsson, M.C., Bergman, K.-O. \& Milberg, P. 2013. Using sex pheromone and a multi-scale approach to predict the distribution of a rare saproxylic beetle. PLoS ONE 8(6), e66149.

Oleksa, A., Ulrich, W. \& Gawroński, R. (2006) Occurrence of the marbled rosechafer (Protaetia lugubris Herbst, Coleoptera, Cetoniidae) in rural avenues in northern Poland. Journal of Insect Conservation, 10, 241-247.

Oleksa, A., Ulrich, W. \& Gawronski, R. (2007) Host tree preferences of hermit beetles (Osmoderma eremita Scop., Coleoptera: Scarabaeidae) in a network of rural avenues in Poland. Polish Journal of Ecology, 55, 315-323.

Palm, T. (1959) Die Holz- und Rindenkäfer der Süd- und Mittelschwedischen Laubbäume (The wood and bark coleoptera of deciduous trees in south and central 
Sweden). Opuscula Entomologiska Supplementum XVI. (in German, English summary).

Ranius, T. (2002) Influence of stand size and quality of tree hollows on saproxylic beetles in Sweden. Biological Conservation, 103, 85-91.

Ranius, T. \& Jansson, N. (2000) The influence of forest regrowth, original canopy cover and tree size on saproxylic beetles associated with old oaks. Biological Conservation, 95, 85-94.

Ranius, T. \& Jansson, N. (2002) A comparison of the three methods to survey saproxylic beetles in hollow oaks. Biodiversity \& Conservation, 11, 1759-1771.

Ranius, T., Aguado, L.O., Antonsson, K., Audisio, P., Ballerio, A., Carpaneto, G.M., Chobot, K., Gjurašin, B., Hanssen, O., Huijbregts, H., Lakatos, F., Martin, O., Neculiseanu, Z., Nikitsky, N.B., Paill, W., Pirnat, A., Rizun, V., Ruicănescu, A., Stegner, J., Süda, I., Szwałko, P., Tamutis, V., Telnov, D., Tsinkevich, V., Versteirt, V., Vignon, V., Vögeli, M. \& Zach, P. (2005) Osmoderma eremita (Coleoptera, Scarabaeidae, Cetoniinae) in Europe. Animal Biodiversity \& Conservation, 28, 1-44.

Ranius, T., Niklasson, M. \& Berg, N. (2009) Development of tree hollows in pedunculate oak (Quercus robur). Forest Ecology \& Management, 257, 303-310.

Ranius, T., Johansson, V. \& Fahrig, L. (2011) Predicting occurance spatial occurrence of beetles and pseudoscorpions in hollow oaks in southeastern Sweden. Biodiversity \& Conservation, 20, 2027-2040.

Rita, H. \& Komonen, A. (2008) Odds ratio: an ecologically sound tool to compare proportions. Annales Zoologici Fennici, 45, 66-72.

Speight, M.C.D. (1989) Saproxylic invertebrates and their conservation. Council of Europe, Strasbourg.

Sverdrup-Thygeson, A., Skarpaas O. \& Ödegaard, F. (2009) Hollow oaks and beetle conservation: the significance of the surroundings. Biodiversity \& Conservation, 19, 837-852.

Tavakilian, G., Berkov, A. \& Meuer-Grimes, B. (1997) Neotropical tree species and their faunas of Xylophagus Longicorns (Coleoptera: Cerambycide) in French Guiana. The Botanical Review, 63, 303-305.

Vasiliauskas, R., Sunhede, S. \& Stenlid, J. (2003) Distribution, status and biology of oak polypores in Baltic Sea region. In: I.M. Thomsen (ed.) Forest health problems in older forest stands. Proceedings of the Nordic/Baltic Forest Pathology Meeting, Denmark, September 2002, Reports No. 13, Danish Centre for Forest, Landscape and Planning, Hørsholm.

Wu, J., Yu, X.-D. \& Zhou, H.-Z. (2008) The saproxylic beetle assemblage associated with different host trees in Southwest China. Insect Science, 15, 251-261. 


\section{Figures}

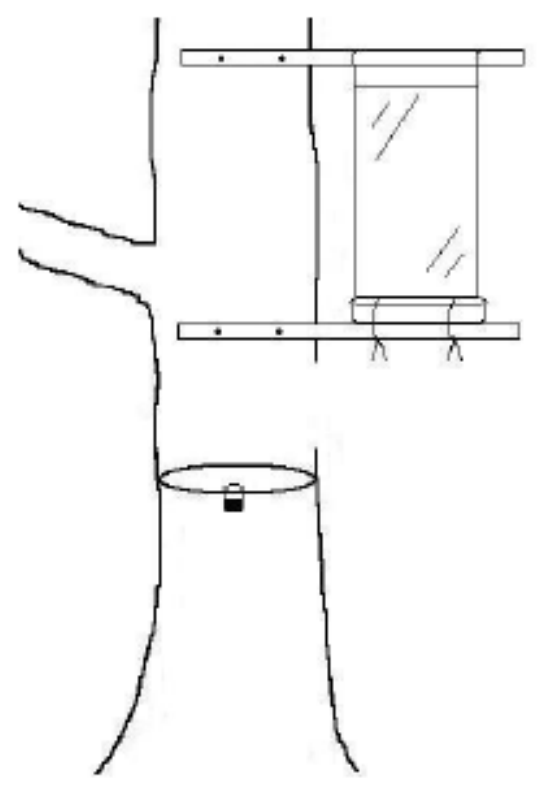

Figure 1

Fig. 1. The pitfall and window traps used in the study to collect saproxylic beetles. 


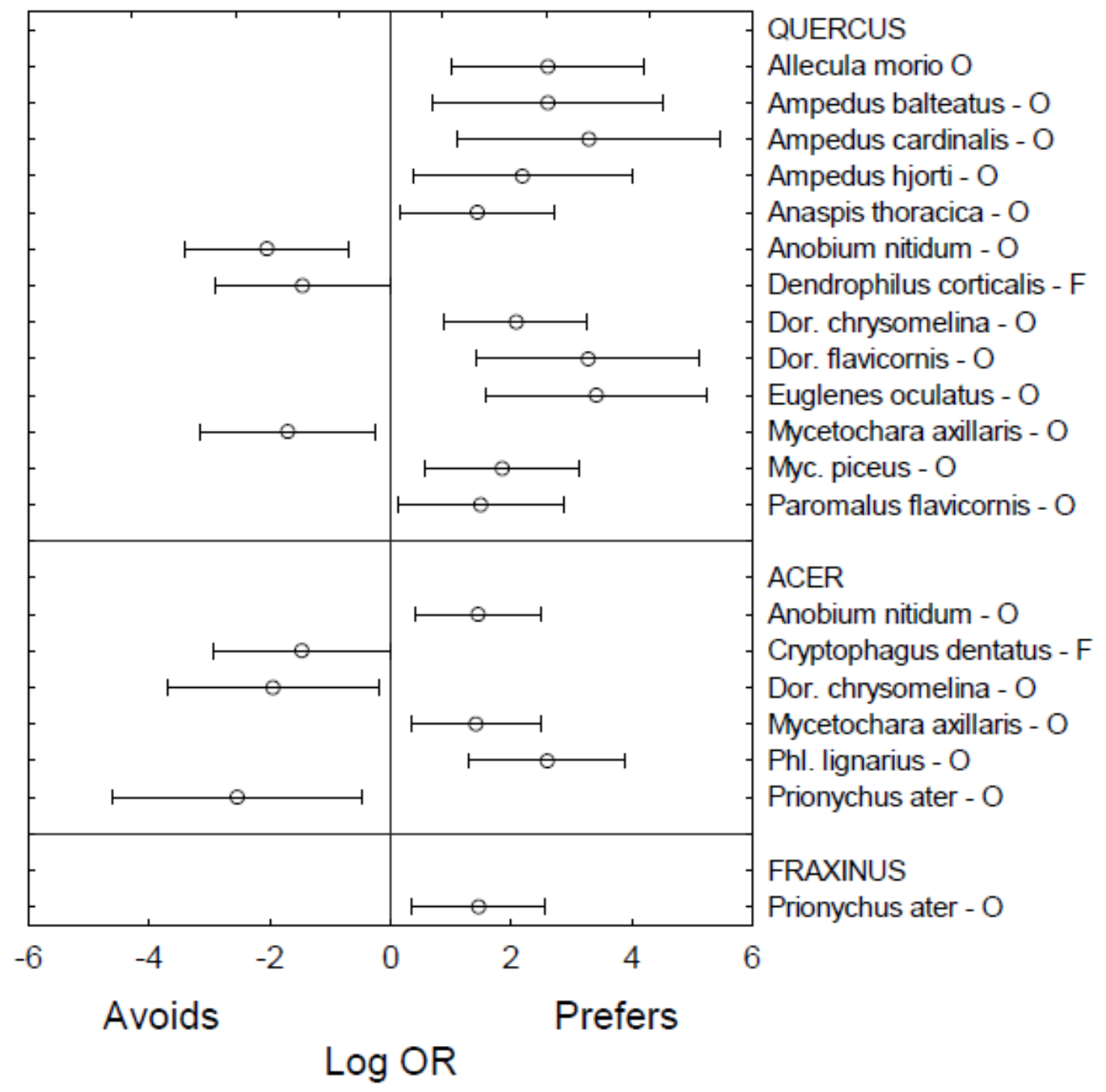

Fig. 2. Beetle species with significantly different odds of being recorded.

2a) Species recorded in at least one the of the trap types on one tree species compared with their recorded presence on the three other tree species. 


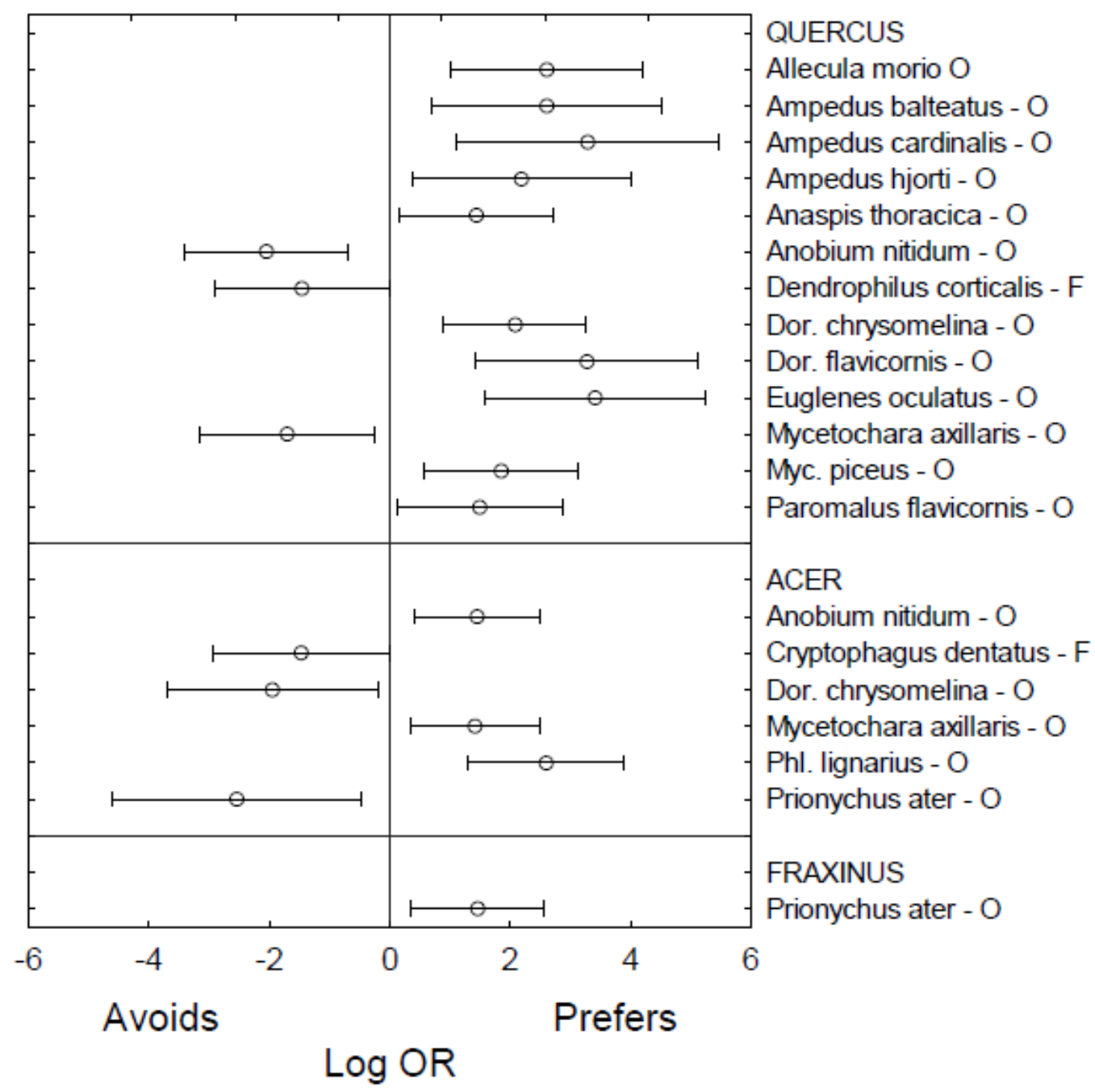

Fig. 2. Beetle species with significantly different odds of being recorded.

2b) Species recorded in both trap types and where the joint evidence from both trap types suggested significant preferences for one tree species over the others. Bars show 95\% confidence interval; the zero reference line indicates no preference. Cry. $=$ Cryptophagus $;$ Den. $=$ Dendrophilus; Dor. $=$ Dorcatoma $;$ Gas. $=$ Gastrallus $;$ Myc. $=$ Mycetophagus $;$ Phl. $=$ Phloeophagus $;$ Tha.$=$ Thamiaraea $. \mathrm{F}=$ facultative saproxylic; $\mathrm{O}=$ obligate saproxylic. 


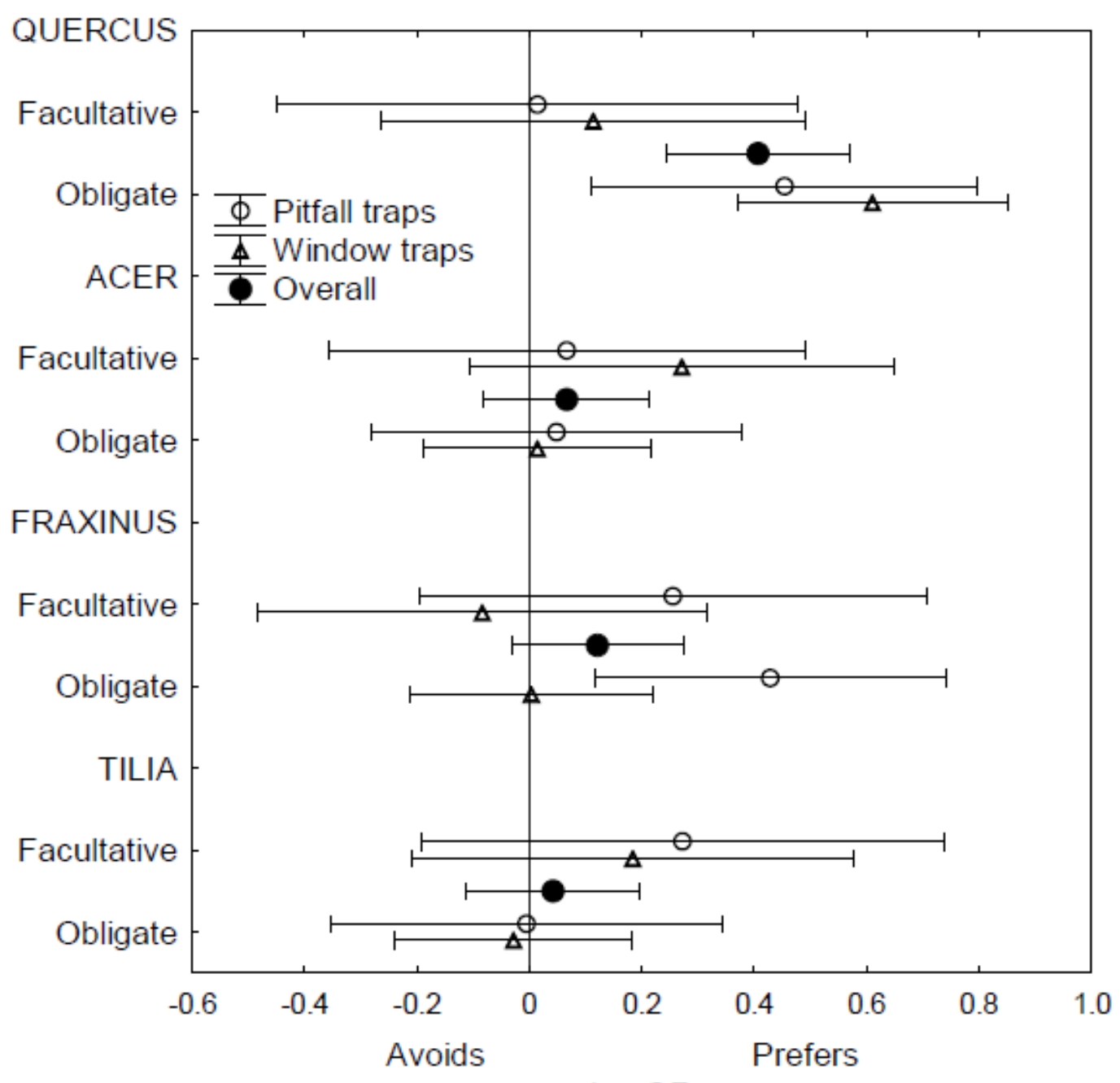

$\log$ OR

Fig. 3. Meta-analysis of species-wise $\log$ (odds ratios) grouped according to tree species, trap type, and whether considered obligate or facultative saproxylic. Bars show $95 \%$ confidence interval; the zero reference line indicates no preference. 


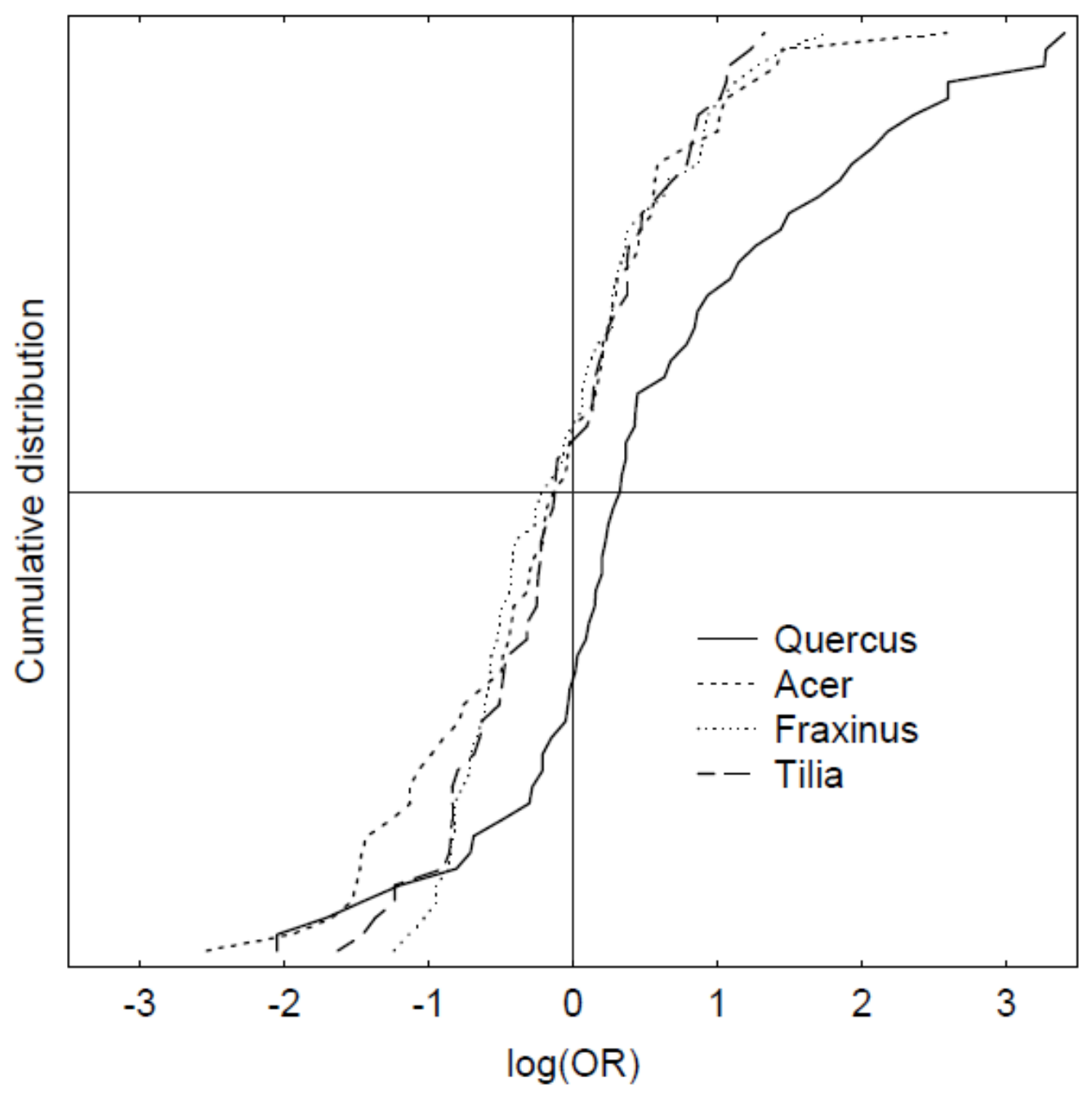

Fig. 4. Distribution of $\log$ (odds ratios) from species-wise meta-analyses contrasting one tree species against the other three. 